\title{
EL PRIMER LIBRO De LeSter EMBReE
}

\section{THE FIRST BOOK BY LESTER EMBREE}

\author{
Antonio Zirión Quijano \\ Universidad Nacional Autónoma de México \\ azirionq@yahoo.com.mx
}

\begin{abstract}
PREFACIO
Tengo razones - buenas razones - para estar seguro de que a Lester Embree le habría gustado mucho ver este pequeño texto publicado, e incluso quizás precisamente, por primera vez, en este volumen de homenaje. Fue el texto que leí en la presentación que hicimos conjuntamente, durante el Coloquio "MerleauPonty viviente" que tuvo lugar en Morelia en 2008, de los dos libros suyos que publicamos en la Serie Fenomenología de la casa editorial moreliana jitanjáfora ${ }^{1}$. Decidimos repartirnos los libros: yo hablaría de Análisis reflexivo (volumen 2 de la Serie), y él de Fenomenología continuada (volumen 7 de la misma). No recuerdo si él llevaba un texto preparado para la ocasión, y mucho menos qué sería de él si acaso lo llevaba. Creo que, de haberlo él llevado, habría llegado en algún momento a mis archivos; pero no lo he hallado en ellos hasta ahora.

Mi amistad con Lester Embree había comenzado once años antes, cuando a finales de octubre de 1997 lo visité en su casa de Delray Beach, en Florida, para darle a conocer a él y a Bill McKenna, a quien también conocí en ese viaje, los proyectos del Diccionario Husserl y del Glosario-Guía para Traducir a Husserl. Desde entonces, sin duda, empezaron a serme familiares no sólo esos rasgos de la personalidad académica o profesional de Lester que son tan bien conocidos por

\footnotetext{
${ }^{1}$ Ver nota 4 abajo [N. del E.].
} 
sus colegas - su preferencia absoluta por los trabajos dirigidos "a las cosas mismas" frente a su relativo desdén por los trabajos que él calificaba como filológicos; su concepción de la fenomenología, o del meollo de la fenomenología, como análisis reflexivo; su inclinación por las disciplinas culturales, o por sus temas y problemas, y su desinterés por las ciencias "duras"; su gran apreciación y creciente constatación de la expansión "planetaria" de lo que él llamaba la "tradición fenomenológica"-, sino también algunos rasgos menos públicos, pero que definían mejor al hombre - su dedicación a un ambientalismo que bien puede decirse "doméstico"; su sensibilidad ante la enorme diversidad cultural, étnica y social que es posible "encontrar" (utilizo el término en el sentido de Embree; léase Análisis reflexivo) en los Estados Unidos (y luego también, obviamente, en el mundo), y su afán y su gusto por inculcarla en sus alumnos; y por encima de todo eso, o en el frente de todo eso, su carácter abierto y ligero, su buen humor, su resistencia casi infantil ante la solemnidad y la severidad...

No supimos, ni Lester ni Bill McKenna ni yo, descubrir la forma de establecer algún tipo de colaboración de que pudieran beneficiarse los proyectos a los que me he referido. En cambio, dio inicio una relación que pudo ser fructífera en otros terrenos. Yo entré, sin proponérmelo y como de la manera más natural del mundo, a formar parte del gran proyecto de Lester -o, casi diría, de su misión profesional- de difusión y promoción a gran escala de la fenomenología, en el cual ponía siempre en juego una asombrosa creatividad y una gran habilidad para generar redes de comunicación e información, instituciones y proyectos colectivos. Independientemente de lo que su amistad significó para mi vida personal y profesional - gracias a él, por ejemplo, me hice miembro del Husserl Circle en 1999, y entré en contacto con muchos de los más destacados colegas del movimiento fenomenológico en los Estados Unidos y en el mundo ${ }^{2}-$, su compañía y su constante impulso nos alentaron siempre en la tarea colectiva de afincar y dar alientos a la fenomenología en México y en América Latina. No sólo

${ }^{2}$ En 2002 participé, por invitación suya, en el que fue llamado Primer Congreso Coreano-Norteamericano de Fenomenología, que organizó Nam In Lee (por iniciativa de Lester Embree, claro está) en Seúl, Corea, dedicado a la temática de la tecnología, la naturaleza y la vida a la luz de la fenomenología; y, en 2011, participé, también por invitación de Lester, en un encuentro en Nueva Orleans cuyos trabajos habrían de formar la base de un libro conmemorativo del centenario del Primer libro de las Ideas de Husserl. El resultado de este encuentro fue, en efecto, el libro Husserl's Ideen, editado por Lester Embree y Tom Nenon y publicado en 2013. El trabajo que presenté en el Congreso de Seúl se convirtió en mi aportación al homenaje que se le rindió a Lester Embree por sus 70 años y que se plasmó en el libro Advancing Phenomenology. Essays in Honor of Lester Embree, editado por Tom Nenon y Philip Blosser y publicado en 2010. 
fue Lester, como lo digo en el texto, testigo de honor en la fundación del Círculo Latinoamericano de Fenomenología, en Puebla, México, en ese mismo año de 1999; también participó activamente en el Primer Coloquio Latinoamericano de Fenomenología que tuvo lugar entonces, y más tarde en los Coloquios Tercero y Cuarto, que se desarrollaron, respectivamente, en Perú en 2004 y en Bogotá en 2007. En este último, por cierto, se encargó de organizar un Panel de Discusión acerca de lo que llamaba el Quinto periodo de la fenomenología ${ }^{3}$, que era en su opinión el periodo en el que nos encontrábamos entonces y en el que seguramente aún nos encontramos ahora, y que se caracteriza - dicho un poco simplificadamente- por la atención preferente sobre los fenómenos de la cultura o los fenómenos "mundanovitales", señaladamente sobre el fenómeno de la "interculturalidad", y, quizá principalmente, por un florecimiento de la fenomenología fuera del campo de la filosofía y dentro del campo de las disciplinas culturales especiales (sociología, psicología, psiquiatría, enfermería, trabajo social, estética, política...).

Lo que Lester hacía por la fenomenología latinoamericana lo hacía también por la fenomenología española y, en verdad, por la fenomenología en cualquier parte del mundo: impulsar, animar, sumar empeños... Sólo quiero recordar aquí su participación en dos reuniones en que yo también participé. La primera fue en el Congreso de la Sociedad Española de Fenomenología que tuvo lugar en Sevilla a fines de 2000, en el cual -o en sus ocasiones "sociales" - se hizo presente, desbordante, el carácter festivo de Lester; y la segunda, años más tarde, en el Cuarto Congreso de la Organización de Organizaciones Fenomenológicas que se llevó a cabo en Segovia en 2011, en el cual nos acompañó en la entrega que hicimos a Roberto Walton de una primera versión del libro de homenaje que estábamos preparando en la misma Serie Fenomenología en que aparecieron los dos primeros libros de Embree que en 2008 presentábamos.

Pero a pesar de todo lo que relato, quizá lo que más propició una relación en que el intercambio de mensajes de correo electrónico era prácticamente cotidiana, fueron las labores editoriales en torno a los dos libros que Lester accedió a publicar en la Serie Fenomenología, los dos libros que quisimos presentar (y el primero no por primera vez) en ese coloquio de Morelia en 2008.

${ }^{3}$ Quinto periodo después de los periodos de fenomenología realista (1), fenomenología constitutiva (2), fenomenología existencial (3) y fenomenología hermenéutica (4). 
Digo "accedió", aunque no es ésta la palabra justa, sólo porque tampoco parecía muy "justo" que una figura como Lester Embree eligiera un proyecto editorial, y cultural, más bien doméstico, enteramente alejado de los circuitos editoriales y comerciales por los que suele circular, por así decirlo, la cultura académica, y en los que incluso habían sido publicados una buena parte de los libros que el mismo Lester había editado en el pasado. Pero además de eso, Lester también accedió, y esto quiere decir, pues, que él mismo se dio el lujo de hacerlo, a que su primer libro fuera publicado en edición bilingüe, inglés/castellano. Y aquí debo hacer un reconocimiento, que no hice en el texto de la presentación, a la muy cuidada traducción del querido colega argentino Luis Román Rabanaque, quien iniciaba así una serie de traducciones al castellano de textos mayores y menores de Lester Embree publicados aquí y allá. Ya en el texto que sigue menciono las subsecuentes traducciones de Análisis reflexivo al ruso, al japonés, al polaco, al chino y al rumano. No he sabido de más en estos últimos nueve años, pero no es imposible que las haya. Podría verse en esto un afán personal de Lester de promocionarse, ya que él mismo se encargaba de gestionar las traducciones. Pero yo estoy seguro - en la medida en que en estos asuntos puede tenerse una opinión- de que su principal motivo era la difusión generosa de la fenomenología misma. Él, y por consiguiente su libro, o sus libros y otros textos, eran instrumentos de una misión a la que había consagrado su vida profesional; misión que no sólo consistía en fomentar los trabajos fenomenológicos en sentido "genérico", sino los trabajos fenomenológicos en que se avanzara en el análisis reflexivo sobre los asuntos y los problemas mismos, con el fin de cubrir una laguna que Lester veía cómo se ampliaba cada vez más, hasta casi poder decir: la filología (el desierto) está creciendo... Descontemos la exageración y tendremos una idea del espíritu que movía a Lester en todos sus trabajos, en todos sus numerosísimos viajes, en su incansable e ingeniosísima y talentosísima labor de ver brotar o hacer brotar fenomenología hasta debajo de las piedras.

Esto no quiere ser sarcástico, pero sí quiere apropiarse un poco de ese carácter ligero, bromista, que Lester desplegaba a manos llenas a la primera provocación. Sin duda, había siempre un gran fondo de seriedad en sus propuestas y en sus convicciones. Pero también había en él una conciencia, a veces inocultable, de estar forzando levemente las nociones de las tendencias y de las tradiciones, de las convicciones y de los prospectos, nociones que no siempre se aliaban de la manera que él creía verlas o quería verlas aliarse. 
Pero nada de esto lo juzga en definitiva, pues aquí un juicio definitivo no viene al caso. Sólo quizá lo presenta (y ese es mi objetivo) como una persona real, no como un ídolo ficticio, como una estatua en su pedestal. Por lo demás, lo que yo tengo que agradecerle a Lester Embree compensa con creces lo muy poco que podría acaso criticarle, aunque aquel agradecimiento sea una cuestión íntimamente personal y estas críticas apunten, o pretendan apuntar, a situaciones muy serias de metodología científica, relativas al sentido y a la misión de la fenomenología en este planeta. Y quizá todo esto se resume, después de todo, en un dilema que podría plantearse así: o bien yo no soy tan optimista como lo fue Lester Embree en relación con la expansión planetaria de la fenomenología, o bien mi visión no tiene el alcance o la profundidad que sí tuvo la de Lester en relación con ese fenómeno cultural que es el desarrollo de la tradición fenomenológica. Pero recuérdese que él era el experto en el tema de los fenómenos culturales...

Para terminar con lo que no digo en el texto que sigue sobre Análisis reflexivo, vale la pena destacar el buen tino de Lester, que en esto fue auxiliado por Ma Luz Pintos, en la elección de las ilustraciones del libro, todas las cuales reproducen cuadros del pintor gallego Fernando Álvarez de Sotomayor. En particular el elegido para la portada - Comida de boda en Bergantiños - representa muy hermosamente el hecho cultural prototípico de una comida en sociedad, muy apto para ser sometido a análisis reflexivo.

También la ilustración de la portada del segundo de sus libros en la Serie Fenomenología (y en su currículo), la Fenomenología continuada. Contribuciones al análisis reflexivo de la cultura, muestra ese mismo tino, y en mi opinión, algo más todavía: la fotografía de Brian Atkinson no sólo ilustra también un fenómeno cultural de los más extendidos y primordiales como es la agricultura, sino que es una manera de celebrar ese otro fenómeno de la interculturalidad que le era tan querido como la comida en sociedad: Lester Embree, el autor estadounidense de análisis reflexivos y él más importante promotor de la fenomenología, lato sensu, a nivel mundial, se mezcla, con solidaridad y con gozo, con las manos michoacanas que hicieron sus $\operatorname{libros}^{4}$, con los traductores iberoamericanos que pusieron

\footnotetext{
${ }^{4}$ Todos los libros de jitanjáfora llevan en la portadilla la leyenda "Hechos a mano por un michoacano". El nombre completo de la editorial es jitanjáfora Morelia Editorial" (así, sin la mayúscula inicial y con las cursivas). Morelia, antes Valladolid, es la capital del estado mexicano de Michoacán.
} 
en castellano los textos del volumen ${ }^{5}$, y con ese campesino mexicano que en la foto ara su campo con una yunta de bueyes. El libro mismo, que al estilo de Embree analiza reflexivamente algunas de las que llama "dimensiones poco exploradas del mundo de la vida" (como las diferencias generacionales, la etnofobia, las actitudes de clase, la dialectología de género, la salud de los ecosistemas), y que también incluye algunas "reflexiones filosóficas" sobre la cultura y las disciplinas culturales, sobre el valor y la acción, es un dignísimo representante, sin ninguna duda, de la fenomenología propia del Quinto periodo, el periodo de la fenomenología del "mundo de la vida", si así se puede resumir.

Durante los últimos años vi muy poco a Lester Embree y me escribí muy poco con él. Pero creo estar seguro de que nunca dejé de ser para él, para su imponente proyecto cultural, lo que él decretó que yo era desde que nos conocimos en su casa de Florida: "our man in Mexico". Cuando le conté hace unos años que había muerto mi hermano mayor, Lester me dijo: "Ahora lo vas a tener más presente que cuando estaba vivo". Y tuvo razón. Aunque la muerte de Lester Embree nos haya hecho la impresión de una contradicción, de un imposible, como si el simple viento hubiera podido derribar un roble, no sería extraño que también pudiera devolvernos su presencia.

\section{PARA LA PRESENTACIÓN DE ANÁLISIS REFLEXIVO. UNA PRIMERA INTRODUCCIÓN A LA} INVESTIGACIÓN FENOMENOLÓGICA DE LESTER EMBREE

Aunque es muy posible que Lester Embree, que aquí nos acompaña, esté muy rápidamente dejando de necesitar presentación en este lugar, quiero referirme un poco a su personalidad dentro del movimiento fenomenológico mundial contemporáneo, porque de ese modo quizá se advierta con mayor nitidez la singularidad del libro que tengo a mi cargo presentar, que es el primero de los dos que ha publicado su autor dentro de la Serie Fenomenología de la editorial jitanjáfora. Desde mucho antes de la publicación de este libro en 2004, Lester Embree era ya, sin ninguna duda, el más destacado promotor de la fenomenología y el más activo animador de las relaciones interpersonales, intercomunitarias, internacionales e interorganizacionales de los fenomenólogos a nivel mundial, y tenía detrás de sí una copiosísima labor editorial. Llevaba ya

${ }^{5}$ Claudia Martínez U., Jesús M. Díaz, Manuel Álvarez Pérez, María del Carmen Paredes Martín, Pablo Hermida Lazcano y Jonathan Camargo. 
también muchos años como presidente del Center for Advanced Research in Phenomenology, desde donde había organizado incansable e incesantemente reuniones nacionales e internacionales de fenomenología y coordinado varias colecciones de libros, de las cuales la más importante es quizá la llamada Contributions to Phenomenology, que publica la editorial Springer y que a la fecha cuenta con 57 volúmenes, en muchos de los cuales Embree ha tenido una participación directa. Dentro de esta colección, como volumen 18, se publicó en 1997 la Encyclopedia of Phenomenology, de la que Lester fue editor general y que fue la primera publicación de su tipo. $Y$ no puede olvidarse su enorme y generosa labor como editor, comentador, estudioso, intérprete y difusor de la obra de sus dos maestros, Aron Gurwitsch y Dorion Cairns, y de un tercer fenomenólogo que por poco no pudo ser su maestro: Alfred Schutz. Cuando el libro que ahora presentamos se planeó, Lester Embree ya había tenido su última gran idea en lo que concierne a la promoción de la reunión, la colaboración y el trabajo conjunto de los fenomenólogos en todo el mundo: en 2002 en Praga se había ya fundado gracias a su aliento la Organización de Organizaciones de Fenomenología, que este año tendrá en Hong Kong su tercera reunión cuatrianual. Pero ésta no ha sido, por supuesto, la única organización de fenomenólogos que Lester ha impulsado o inspirado, aunque sea la más abarcadora: por sólo citar otra que nos toca de cerca, Lester tuvo su papel como impulsor y estampó su firma como testigo de honor en la fundación del Círculo Latinoamericano de Fenomenología en Puebla, en 1999. Pero a pesar de toda esta labor, cuya sola lectura en su curriculum vitae es ya fatigosa, Lester Embree no había publicado antes de este libro un sólo libro suyo, propio, original. Múltiples ensayos, reseñas, ponencias, artículos, conferencias, ediciones de libros y de todo tipo de textos, libros en colaboración, antologías, etc., etc., en cantidades respetables, sí, pero este Análisis reflexivo. Una primera introducción a la investigación fenomenológica es en efecto, con todo, el primer libro original de Embree, y es la publicación que él mismo pone a la cabeza de todas sus publicaciones en la lista que hace de ellas en su curriculum.

Para la Serie Fenomenología, que apenas estaba en gestación, la publicación de este libro como su volumen 2 fue un gran honor y además una oportunidad de corresponder a la generosidad de Embree y sobre todo a su sensibilidad ante los desequilibrios en las relaciones interlingüísticas. A lo mejor a él no le va a gustar que lo diga, pero él pagó de su bolsillo la traducción al castellano del texto, 
cuya versión original en inglés está también publicada en el mismo libro. Por eso el título también es doble: en castellano y en inglés. Posteriormente ha sido traducido al ruso, al japonés, al polaco, al chino y al rumano, y ha tenido una nueva edición solamente en inglés. Pero estas son otras historias. Para la Serie Fenomenología fue una gran suerte, además, poder publicar este libro porque se trata de una introducción a la fenomenología, y éste era precisamente uno de los rubros que la Serie se había propuesto cubrir. Hasta ahora es la única introducción a la fenomenología que ha publicado la serie, aunque otra se está cocinando; y como introducción es realmente original. Siempre han faltado en castellano las introducciones a la fenomenología, y no sólo a la fenomenología husserliana. Las existentes hasta hace poco eran o escabrosas o sesgadas o contenían algunas tergiversaciones desorientadoras. E incluso las que provenían de la mano misma de Husserl y que quien les habla tuvo la ocurrencia de traducir hace algunos años - Las conferencias de París y El artículo de la Encyclopaedia Britannica- no son textos fáciles de seguir sin ayuda por alguien que justamente lo que quiere es introducirse en la fenomenología. No diré que la de Embree es o será la introducción definitiva a la fenomenología en castellano, pero sí que es una buena introducción, una introducción amigable, accesible, y ciertamente muy original.

Lo primero que hay que decir sobre ella es que se trata de una introducción a la fenomenología considerada no como un "cuerpo de resultados" que deban ser conocidos y acumulados en la memoria individual o colectiva, sino como un método o como un enfoque que puede uno aprender a practicar y en el que uno puede entrenarse. Este libro es una herramienta para iniciar este entrenamiento. Está dirigido, entonces, no precisamente a estudiantes que quieran aprender las tesis y verdades de la fenomenología, sino a aprendices de fenomenología. Este sesgo didáctico va de la mano de una idea que Embree tiene desde hace muchos años y que, más que una idea, es en él una obsesión, pero a mi modo de ver una obsesión plenamente justificada por el estado de cosas existente en el mundo de la fenomenología. Embree distingue lo que llama las indagaciones fenomenológicas en dos especies o dos vertientes: la erudición y la investigación propiamente dicha; la primera, la erudición, consiste en la exposición, el comentario, y con suerte, la crítica y la traducción o elaboración de textos auténticamente fenomenológicos, o de fenomenólogos que realmente se aplicaron al análisis y la descripción de las cosas mismas, pero no se ocupa ella 
misma con las cosas mismas. Esto es lo que hace, por su parte, la investigación fenomenológica propiamente dicha: ocuparse con las cosas mismas, analizarlas y describirlas. Y es ésta la que a Embree le interesa fomentar. Con razón, pues todos estaremos de acuerdo en que lo que predomina, con mucho, y no sólo en nuestro medio local o nacional, sino mundial, y no sólo en la fenomenología, sino en el resto de la filosofía y de las disciplinas humanas o humanísticas, es erudición, que no por ser indispensable y valiosísima precisamente para los fines de las investigación de las cosas mismas, no es ella un fin en sí misma. Es una cuestión de balance y de equilibrio, y en lo que Embree insiste es en el enorme desequilibrio existente. Probablemente más del ochenta por ciento (ésta cifra va por mi cuenta y riesgo) de los textos de todo tipo (libros, artículos, etc.) que se publican en filosofía y ciencias humanas son textos de erudición. Y lo malo no es sólo este gran desequilibrio, sino la suerte de simulación que hay en el hecho de pensar que esta erudición es la auténtica investigación. Sobre este tema hay aspectos que nos podrían poner a discutir largo tiempo: no todo es tan sencillo como está expuesto y hay una imbricación entre la investigación y la erudición que se muestra ya desde por lo menos la Metafísica de Aristóteles. Y yo mismo seré el último en denigrar la erudición, pues me he dedicado a ella durante la mayor parte de mi vida profesional. Además, creo que puede distinguirse todavía entre una erudición competente, consciente de su situación histórica y de sus limitaciones, y una erudición incompetente o incluso irresponsable, que efectivamente confunde el fin con los medios y la investigación con una interminable ristra de textos sobre textos sobre textos... Pero precisamente porque esta erudición es la predominante, resulta muy pertinente y oportuno un libro como esta introducción a la investigación fenomenológica, que es una invitación a refrescarse la cabeza, a dejar la erudición a un lado, o detrás, que es donde debe estar, y a enfrentarse como por vez primera con las cosas mismas. Esta introducción es original, pues, porque es una introducción a la investigación fenomenológica, y no a la fenomenología histórica o a la historia de la fenomenología.

Junto a la evitación de la erudición, hay por cierto otro propósito central o fundamental de esta introducción que debe destacarse, y que es la evitación de la argumentación. Como la erudición, la argumentación (o acaso habría que decir más bien el exceso de argumentación, o el uso exclusivo o preponderante de argumentaciones) es considerada aquí como un vicio, sólo que en este caso no 
es un vicio achacable a los fenomenólogos, sino a filósofos o investigadores de otras tendencias contra las que aquí se previene. Los fenomenólogos no presentan, por regla general, argumentos, sino análisis. Y es justamente este análisis o este tipo de análisis el que aquí se quiere mostrar y describir.

Otro toque de originalidad de esta introducción consiste en que ella misma es un ejemplo de lo que predica: quiero decir, no solamente se propone impulsar y fomentar la investigación fenomenológica sobre las cosas mismas - lo que se podría también hacer sobre la base de una buena cantidad de erudición, con citas textuales de fenomenólogos que han recomendado también ir a las cosas mismas, empezando por Husserl, y con comentarios muy sustanciosos sobre esas citas-, sino que lo hace en una exposición directa, clara y llana, de los recursos metódicos que propone, que son justamente las cosas mismas de esta introducción: la observación, la información, la reflexión, el análisis, la descripción, la clasificación, el examen. El libro contiene, por ejemplo, una sola nota al pie, y ésta en el "Prefacio para instructores". Y como las remisiones a otros autores son poquísimas, el lector puede sentir que en efecto con esta introducción comienza todo. Naturalmente que en este libro no comienza todo, pero es muy importante el mensaje de que con nada más que este libro el lector puede comenzar a poner en práctica el método que se le propone.

También en esto es consecuente el libro, pues enseña a utilizar este método mediante su puesta en práctica. Es decir: al mismo tiempo que se va describiendo, la herramienta se va utilizando. Esta herramienta o este método, o, como también lo llama el autor, este enfoque, es el fenomenológico, pero ciertamente reducido, por así decirlo, a su mínima expresión, a su núcleo más esencial. A este núcleo esencial se le Ilama aquí análisis reflexivo. El análisis reflexivo, es decir, la fenomenología en esta versión medular o "concisa", tiene como tema "procesos intentivos y objetos en tanto que intencionados", lo que diríamos, en una versión algo más husserliana, vivencias intencionales, o procesos vivenciales intencionales, y objetos en tanto que correlatos de esos procesos vivenciales. Embree nos da todavía una formulación distinta, también muy suya: según ésta, el análisis reflexivo se ocupa "del encuentro de objetos (o del encontrar objetos) y de los objetos en tanto que encontrados". Pero estas mismas definiciones pueden ser revisadas, confirmadas o puestas en cuestión por el lector en la medida en que la exposición avanza y él mismo va siguiendo los análisis reflexivos que el autor expone y ejecutándolos él mismo por su parte, 
puesto que es innegable que es posible someter a análisis reflexivo al mismo análisis reflexivo, una posibilidad que el autor no explora aquí mayormente pero que desde luego admite.

Los procesos y objetos (o determinaciones) en los que el autor pone el acento son los llamados culturales, frente a los naturales o naturalistas. $Y$ no es que ignore estos últimos, sino que considera como parte de su misión, si lo interpreto correctamente, contrarrestar el naturalismo que, emparejado con el objetivismo y el cientificismo, han imperado en el pensamiento occidental. Destacar las determinaciones, propiedades o rasgos culturales, no sólo va de acuerdo con un propósito básico de la fenomenología desde sus orígenes en el mismo Husserl, sino que es también un reconocimiento de lo que Embree cree que es la tendencia o vertiente más importante en nuestros días en el movimiento o en la tradición fenomenológica, como él la llama, hasta el punto de que ese interés dominante por la cultura constituye una quinta etapa de esa tradición. En este punto, este libro, Análisis reflexivo, apunta ya veladamente al otro libro que aquí presentamos, Fenomenología continuada, que comienza precisamente por un repaso de las cinco etapas de la tradición fenomenológica para situar justamente su contenido, es decir, sus "Contribuciones al análisis reflexivo de la cultura", como reza su subtítulo. No ahondaré aquí más en la relación entre ambos libros, pero no puedo dejar de decir algo que de sólo mirar los títulos y subtítulos de ambos libros se puede fácilmente advertir: el primero, Análisis reflexivo. Una primera introducción a la investigación fenomenológica, es una exposición y un manual práctico del método que se aplica en el segundo libro, es decir, en Fenomenología continuada. Contribuciones al análisis reflexivo de la cultura.

Pero antes de ceder la palabra a quien va a hablarles acerca de este segundo libro, quiero todavía subrayar un par de cosas. La primera es la presencia de ejercicios al final de cada capítulo de Análisis reflexivo. Esto es totalmente inusitado en una introducción a la fenomenología y da una buena idea del carácter práctico del libro. Los ejercicios se presentan, como en un buen manual práctico, al final de cada capítulo. Algunos de ellos sirven como repaso o reforzamiento de lo aprendido en el capítulo, que es siempre algún aspecto, elemento o dimensión importante del análisis reflexivo, pero otros son auténticos motivos para ejercitarse en el análisis reflexivo mismo. No se presentan, sin embargo, ningunas respuestas o soluciones a los ejercicios, lo que quizá indica que el autor quiso evitar toda posibilidad de que el lector hiciera trampa, pero 
que también apunta al hecho de que la fenomenología no es, ni en esta versión nuclear o escueta de ella que es el análisis reflexivo, una ciencia exacta. 0 , finalmente, es que está previsto que el libro sea manejado en el aula con la ayuda de un instructor, quien tendrá también su propio criterio en relación con los ejercicios y su resolución.

Lo segundo, y lo último, que quiero subrayar, es justo este hecho de que, en el análisis reflexivo tal como lo presenta Embree, se trate de una versión escueta de la fenomenología: hay en ella, y en el libro en general, grandes simplificaciones. No sólo se dejan de lado muchas temáticas abordadas por Husserl o por sus más grandes sucesores, lo que se explica fácilmente tratándose de una introducción. También el método mismo está expuesto sin detenerse ni adentrarse en múltiples cuestiones problemáticas cuya ausencia salta a la vista para un filósofo profesional o para alguien familiarizado con textos de investigación o de erudición fenomenológica (no diré para un fenomenólogo bien entrenado, pues éstos, lamentablemente, no abundan). Esta superficialidad es, sin embargo, una superficialidad buscada, y forma parte de la misma estrategia de facilitar la práctica de la investigación fenomenológica. Permítanme citar un pasaje del "Prefacio para instructores" en que el autor se refiere a esta superficialidad con una imagen que me parece muy iluminadora.

Los resultados - dice [los resultados de las decisiones tomadas respecto a qué incluir y qué excluir del texto]- se parecen tal vez a un estadio temprano de una investigación arqueológica donde ha sido excavado únicamente el estrato superior de todo el sitio. Los lugares donde hay que excavar más hondo pueden entonces ser mejor determinados. ${ }^{6}$

Nada impide excavar más hondo en cualquiera de los lugares que han empezado a develarse; pero es importante tener un primer panorama de todo el terreno y de la manera de hacer la excavación. Nada impide tampoco seguir puliendo las herramientas mientras se hace la excavación. Que esta herramienta del análisis reflexivo puede en efecto ayudarnos, como afirma Embree, "a conocer, valorar y obrar de modo más eficaz y responsable", es en mi opinión innegable, con tal, no solamente, de que hayamos trabajado el texto con toda

6 Lester Embree, Análisis reflexivo. Una primera introducción a la investigación fenomenológica / Reflective Analysis. A First Introduction into Phenomenological Investigation, Morelia: jitanjáfora Morelia Editorial (sic), 2003, p. 21. 
exhaustividad, como lo pide su autor, sino de que hayamos aprendido a profundizar en el análisis reflexivo y a excavar realmente más allá de lo que en él se hace. O dicho de otro modo, que resulta una obviedad, el libro será un buen principio de investigación fenomenológica sólo si lo tomamos como un principio y no le pedimos que nos lleve hasta el final. Termino esta presentación con las palabras finales de la Introducción:

La mayoría de las áreas en el campo de la fenomenología no ha sido investigada aun tras un siglo. Los asuntos son complejos; el lenguaje técnico desarrollado hasta el momento rararamente es adecuado; las aplicaciones apenas han comenzado; y se requiere de un esfuerzo disciplinado para alcanzar un punto de vista apropiado desde el cual observar, analizar y describir. ${ }^{7}$

Como se ve, pues, en fenomenología el final no está todavía a la vista de nadie. Casi todo está por hacer.

7 Ibid., p. 61. 